\title{
Cardiac Beriberi in an infant : An Unforgettable Disease
}

1 Prof. Mahmuda Hassan Professor of paediatrics Ad-din Women's Medical College, Dhaka

2 Dr. Afsana Mukti Assistant Professor

3 Dr. Hakimul Haque Associate professor

4 Dr. Masuma Khan Assistant Professor

5

Dr. Marium Begum Associate Pof. of paediatrics Basundhara Ad-din Medical College, Dhaka

6 Dr. Sudipta Roy Assistant Professor

7 Prof. Taslim Uddin Ahmed

8 Dr. Ashraf Uddin Ahmed Associate professor

9 Dr. Sadia Tabassum Assistant registrar (paediatrics) Shahid Sarwardi Medical College

${ }^{10}$ Prof. A R M Luthful Kabir

${ }^{11}$ Prof. Hamidur Rahman

Professor and head

$2,3,4,6,7,8,10,11$

Dept. of Paediatrics

Ad-din Women's Medical College

Correspondence

Prof. Mahmuda Hassan

Prof. of paediatrics

Ad-din Women's Medical College e-mail:

mahmudahasan@yahoo.com

\section{Hassan ${ }^{1}$, A Mukti ${ }^{2}$, H Haque ${ }^{3}$, M Khan ${ }^{4}$, M Begum ${ }^{5}$, S Roy ${ }^{6}$, T U Ahmed ${ }^{7}$, A U Ahmed ${ }^{8}$, S Tabassum ${ }^{9}$, A R M L Kabir ${ }^{10}$, H Rahman ${ }^{11}$}

\section{Introduction}

Thiamine, or vitamin $B_{1}$, is a water-soluble vitamin with a biologically active form known as thiamine pyrophosphate, which plays a critical role in carbohydrate metabolism and produces essential glucoses for energy by acting as coenzyme. ${ }^{1,2}$ Thiamine deficiency (TD), or beriberi, generally refers to the lack of this active form. TD renders pyruvate and some amino acids unavailable in many systems, with the cardiovascular system being particularly vulnerable. Prior studies have demonstrated that TD exerts an unfavorable effect on cardiac contractility in the long term, which can clinically manifest as heart failure. $3,4,5$

As clinically evident TD is now very rare in the developed countries and most patients have no symptoms or signs, its diagnosis is commonly missed without any suspicion. ${ }^{6,7}$ However, when there is an undernourished dietary history of an infant with cardiac symptoms and signs of heart failure, physicians can reasonably suspect this disease. The severity of potential outcomes if it is left untreated makes it essential for cardiologists to have an understanding of this condition and its optimal treatment.

We herein present one case of cardiac beriberi in which optimal and timely treatment induced dramatic clinical improvement.

\section{Case Report}

A 9-month female child presented with the history of respiratory distress and feeding difficulty with vomiting. She had no significant past illness and immunized as per EPI schedule. She was adopted on her $3^{\text {rd. }}$ day of life and from that time was on diluted formula milk up to 5 months. Five months' onward rice gruel was given along with diluted milk till hospital admission and with occasional history of having rice based family food.

Her weight was $7 \mathrm{~kg}$. (below $3^{\text {rd }}$ centile value) and length was $65 \mathrm{~cm}$. (at $3^{\text {rd }}$ centile) and weight for height at $50^{\text {th }}$ centile. Her temperature was $98.8^{\circ} \mathrm{F}$.

On examination baby was afebrile, severely pale with severe respiratory distress which was evidenced by flaring of the ala nasi, fast breathing and severe chest in drawing. Her respiratory rate was 66 breaths per minute, she was centrally cyanosed with $\mathrm{SpO}_{2} 83 \%$ in room air, cyanosis resolved after giving $\mathrm{O}_{2}$ at the rate of 2 liters per minute and $\mathrm{SpO}_{2}$ became normal, $93 \%$ within 10 minute. Her breath sound was vesicular with presence of basal crepitation. Pulse rate was 169/minute, feeble with gallop on auscultation, blood pressure $70 / 30 \mathrm{~mm}$ of $\mathrm{Hg}$. She had tender hepatomegaly, which was $5 \mathrm{~cm}$ enlarged at the right mid clavicular line with the upper border of liver dullness at the right $5^{\text {th }}$ intercostal space. No other organomegaly

Investigations were advised for $\mathrm{CBC}$ with $\mathrm{PBF}$, Blood $C / S$, portable $X$ Ray Chest AP view which revealed cardiomegaly. We had a plan to do echocardiography and ECG.

The baby was kept on nothing per oral with restricted intravenous fluid and $1^{\text {st }}$ dose of furosemide was given.

Without waiting for investigations injectable thiamine was started at a dose of $25 \mathrm{mg} /$ dose twice daily within 1 hour after arrival at hospital. 
Antibiotic was started as per hospital protocol suspecting for bacterial infection. Hemoglobin was $6.3 \%$ and parents were advised to arrange blood for packed red blood cell (PRBC) transfusion.

Surprisingly before transfusion was started and after getting a single dose of furosemide and two doses thiamine baby was improved.

Clinical improvement was noticed within 8 hours after admission and no tachycardia, no tachypnea, liver size reduced to $2 \mathrm{~cm}$ and non-tender.

After 16 hours of her admission, she received PRBC transfusion even after clinical improvement due to severe anaemia. Blood culture, urine culture report had no growth of any organism. Serum electrolytes, serum calcium and the liver function tests were within normal limit.

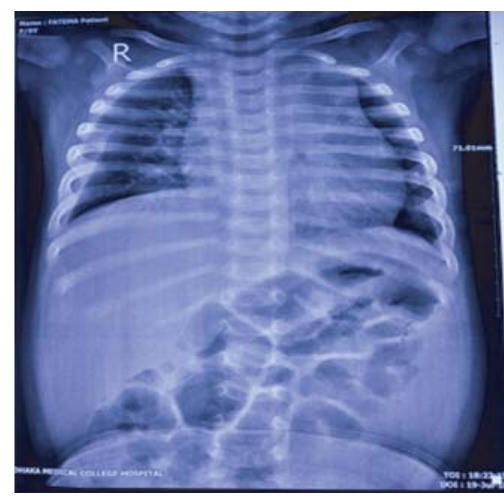

Fig. 1 : Before treatment

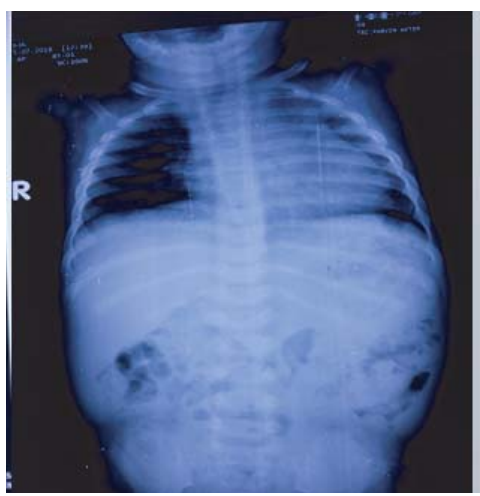

Fig. 2 : After treatment

On $3^{\text {rd }}$ day antibiotic was discontinued after getting c/s report and retained at hospital for 7 days with regular follow up which showed normal vitals with rapid reduction of the liver size to normal and we continued injectable thiamine, multi vitamin and supplemental iron. Another $\mathrm{X}$ ray chest was done on $7^{\text {th }}$ hospital day with normal cardiac shadow with normal lung findings and baby was discharged with advise.

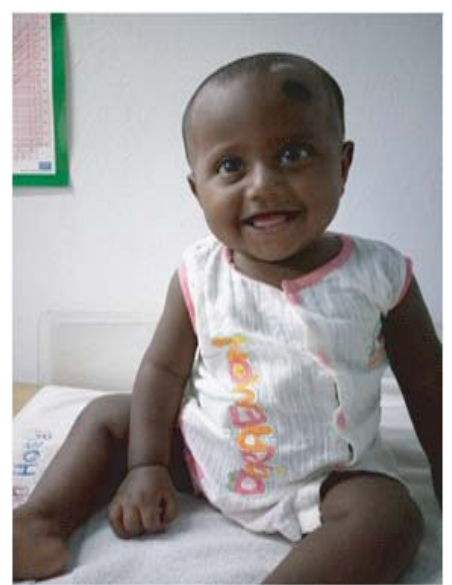

Fig 3 Baby after treatment

\section{Discussion}

Cardiac beriberi has been repeatedly reported for centuries all over the world, although it is very rare in the contemporary era, especially in developed countries. ${ }^{6}$ Many studies have emphasized the need for clinical suspicion of cardiac beriberi in patients presenting with heart failure, because in such cases the appropriate replacement of thiamine can prevent devastating consequences and significant improvement of cardiac function.

Our case was treated with thiamine injection just after admission and dramatic clinical improvement was observed within 8 hours of admission. Other than thiamine baby received single dose of furosemide and oxygen inhalation and intravenous antibiotics. Digoxin was not given because of the rapid improvement.

Currently, the diagnosis of this disease depends on the following three factors: 1) clinical symptoms related to heart failure and a characteristic history of dietary inadequacy, 2) exclusion of other etiologic types of heart disease and 3) therapeutic response to thiamine administration. ${ }^{1}$

Even with the support of sophisticated, contemporary cardiac imaging modalities like echocardiography and?? CMR, the diagnosis of cardiac beriberi is commonly missed because of its rarity. Doctors usually do not suspect beriberi as a cause of TD.

However, the echocardiographic findings for cardiac beriberi are very similar to those for other forms of dilated cardiomyopathy, i.e., a reduction in LV systolic function and LV enlargement with or without valvular regurgitation. As such, we cannot establish a diagnosis of cardiac beriberi based exclusively on echocardiography. ${ }^{10,11,12}$

However, myocardial edema, apart from LV systolic dysfunction, is not a specific finding for cardiac beriberi. Besides this, 
myocardial edema may not always be present in cardiac beriberi. We did not place an order for laboratory confirmation of TD.

For confirmation of TD whole blood thiamine diphosphate (TDP) concentrations, clinical findings and blood TDP levels after therapy is confirmatory for diagnosis Blood levels of thiamine pyruvate, urinary excretion of thiamine and its metabolites may be measured to support and confirm the diagnosis, and the scarcity of any of these may help to confirm the diagnosis of beriberi with the above mentioned three factors. ${ }^{13}$

However, measurement of these chemicals are time consuming and costly, and may also cause delay in diagnosis and treatment and may have fatal outcome. Thus, for these reasons, thiamine replacement as a therapeutic trial is considered the most feasible approach. If the patient responds to this empirical thiamine replacement as we have seen in our case, it is safe to conclude that the heart failure was due to TD. It is important to begin thiamine replacement early if thiamine deficiency is suspected, because of risk of mortality with cardiac beriberi and for morbidity due to permanent psychosis. ${ }^{8}$ Administration of thiamine can even be used as a diagnostic test in cases of acute heart failure or insidious peripheral neuropathy, because of the rapid and dramatic improvement in symptoms if deficiency truly exists.

Prognosis is good for patients with thiamine deficiency that has not progressed to Korsakoff syndrome. In Wernicke-Korsakoff syndrome, psychosis may not improve for months and may be permanent. $^{8}$

\section{Conclusion}

Cardiac beriberi secondary to TD is not straightforward to diagnose because of its nonspecific symptoms and signs. Therefore, a conglomeration of findings from careful history taking, physical examinations, and suspicion by the clinician are helpful and lifesaving.

\section{References}

1. Jones RH., Jr Beriberi heart disease. Circulation. 1959;19:275-283.

2. Astudillo $L$, Degano $B$, Madaule $S$, et al. Development of beriberi heart disease 20 years after gastrojejunostomy. Am J Med. 2003;115:157-158 .

3. Cappelli V, Bottinelli R, Polla B, Reggiani C. Altered contractile properties of rat cardiac muscle during experimental thiamine deficiency and food deprivation. J Mol Cell Cardiol. 1990;22:1095-1106.

4. Sriram K, Manzanares W, Joseph K. Thiamine in nutrition therapy. Nutr Clin Pract. 2012;27:41-50.

5. Wooley JA. Characteristics of thiamin and its relevance to the management of heart failure. Nutr Clin Pract. 2008;23:487-493.

6. Yang JD, Acharya K, Evans M, Marsh JD, Beland S. Beriberi disease: is it still present in the United States? Am J Med. 2012;125:e5.

7. Towbin $A$, Inge $T H$, Garcia VF, et al. Beriberi after gastric bypass surgery in adolescence. J Pediatr. 2004;145:263-267.

8. Russell RM, Suter PM. Chapter 74. Vitamin and Trace Mineral Deficiency and Excess. In: Longo DL, Fauci AS, Kasper DL, Hauser SL, Jameson J, Loscalzo J. eds. Harrison's Principles of Internal Medicine, 18e. New York, NY: McGraw-Hill; 2012

9. Isenberg-Grzeda $\mathrm{E}$, Kutner HE, Nicolson SE. Wernicke-Korsakoff-syndrome: under-recognized and under-treated. Psychocomatics 2012;53: 507-516.

10. Rao SN, Chandak GR. Cardiac beriberi: often a missed diagnosis. J Trop Pediatr. 2010;56:284-285 .

11. Naidoo DP, Gathiram V, Sadhabiriss A, Hassen F. Clinical diagnosis of cardiac beriberi. S Afr Med J. 1990;77:125-127.

12. Lahey WJ, Arst DB, Silver M, Kleeman CR, Kunkel P. Physiologic observations on a case of beriberi heart disease, with a note on the acute effects of thiamine. Am J Med. 1953;14:248-255.

13. Lu J, Frank EL. Rapid HPLC measurement of thiamine and its phosphate esters in whole blood. Clin Chem. 2008;54:901-906. 